\title{
Non Destructive Tests for Evaluation of Railway Platforms: Application of Ground Penetrating Radar
}

\author{
S. Fontul ${ }^{1}$, E. Fortunato ${ }^{1}$, F. De Chiara ${ }^{2}$ and A. Paixão ${ }^{1}$ \\ ${ }^{1}$ LNEC, National Laboratory for Civil Engineering, Lisbon, Portugal \\ 2University of Rome "La Sapienza", Italy
}

Keywords: railway infrastructure, monitoring, ground penetrating radar, dielectric properties.

Identification and diagnosis of railway track problems of the supporting layers is essential to achieve efficient maintenance and safe train operations [1]. Nowadays, maintenance interventions consist of performing different operations such as levelling and tamping of the track, based on the measured geometric parameters. Although these actions restore the track design geometry, they do not solve substructure related problems. Thus, a better maintenance policy should be adopted so that structural problems can be identified and solved earlier, for example by using non-destructive tests $[1,2]$ during monitoring surveys. The ground penetrating radar (GPR) is a non-destructive technique that allows the evaluation of the infrastructure condition almost continuously, enabling, besides the measurement of thickness of layers, the identification of changes in the structure and material condition along the track [2].

This paper presents some GPR tests performed for railway evaluation, both during construction and during service life. The objective was to study different possible applications of this technique to railway tracks. Some of the results obtained are presented in this paper, together with the calibration procedures performed. Moreover, future research lines are addressed, with the aim of improving the GPR testing methodology and, in this way, to optimise the assessment of the track condition.

\section{References}

1 T.R. Sussmann, K.R. Maser, D. Kutrubes, F. Heyns, E.T. Selig, "Development of Ground Penetrating Radar for railway infrastructure condition detection", 14th EEGS Symposium on the Application of Geophysics to Engineering and Environmental Problems (SAGEEP), Denver, CO, March, 2001.

2 S. Fontul, E. Fortunato, F. De Chiara, "Non-Destructive Tests for Railway Infrastructure Stiffness Evaluation", in B.H.V. Topping, Y. Tsompanakis, (Editors), "Proceedings of the Thirteenth International Conference on Civil, Structural and Environmental Engineering Computing", Civil-Comp Press, Stirlingshire, UK, Paper 16, 2011. doi:10.4203/ccp. 96.16 